(C2019, Elsevier. Licensed under the Creative Commons Attribution-NonCommercialNoDerivatives 4.0 International http://creativecommons.org/about/downloads 


\title{
Oxytocin reduces post-stress sweet snack intake in women without attenuating salivary cortisol
}

\author{
V. Burmester ${ }^{1}$, E. L. Gibson ${ }^{2}$, G. Butler ${ }^{1}$, A. Bailey ${ }^{3}, \&$ P. Terry ${ }^{1 *}$
}

${ }^{1}$ Department of Psychology, School of Law, Social and Behavioural Sciences, Kingston University, Penrhyn Road, Kingston upon Thames, Surrey KT1 2EE

${ }^{2}$ Department of Psychology, Whitelands College, University of Roehampton, London SW15 4JD, UK

${ }^{3}$ Institute of Medical and Biomedical Education, St George's, University of London, Cranmer Terrace, London SW17 0RE.

*Corresponding author: Professor Philip Terry, Department of Psychology, School of Law, Social and Behavioural Sciences, Kingston University, Penrhyn Road, Kingston upon Thames p.terry@kingston.ac.uk

Declarations of interest: none.

Key words: oxytocin, anorectic, hedonic eating, cortisol, reward 


\begin{abstract}
Intranasal oxytocin produces anorectic effects on snack intake in men when tested in the absence of deprivation-induced hunger, but its effects on food intake in women without eating disorders have not been reported. Oxytocin may reduce food intake by reducing stress eating, since it inhibits ACTH release. The present study adopted a double-blind, repeated measures and fully concealed crossover protocol in which 38 women self-administered 24 IU of oxytocin or placebo intranasally, ate lunch, and underwent two consecutive stress tests. Snack intake was assessed 15-20 minutes after lunch, via a sham taste test. Salivary cortisol was measured throughout the test period every 15 minutes. Oxytocin significantly reduced sweet fatty snack intake independently of any effect on salivary cortisol, which declined over time at a similar rate after either drug or placebo. Ratings of sweet taste were slightly reduced by oxytocin, but only in self-reported stress eaters. These results differ from previous studies with men that found an effect of oxytocin on postprandial cortisol levels. However, previous research assayed the less active form of plasma cortisol and did not control for protein intake, which can drive elevated cortisol. The finding that oxytocin reduces snack intake in females after acute stress has important implications for appetite regulation and its treatment in obese people and in those with eating disorders.
\end{abstract}




\section{INTRODUCTION}

Oxytocin (OT) is a hypothalamic neuropeptide hormone, released into the circulation via the posterior pituitary gland that also has central actions known to affect social behaviours (Jones, Barrera, Brothers, Ring, \& Wahlestedt, 2017). In experimental animals and humans, OT inhibits palatable food intake and alters macronutrient metabolism (Leng \& Sabatier, 2017; Leslie, Silva, Paloyelis, Blevins, \& Treasure, 2018). OT also regulates the hypothalamo-pituitary-adrenal axis (HPA) and is released both centrally and peripherally in response to both psychological (Carter \& Altemus, 1997; Onaka, Takayanagi, \& Yoshida, 2012) and physical stress (Cardoso, Ellenbogen, Orlando, Bacon, \& Joober, 2013). However, relatively little is known about the role of OT in mediating either the hypophagic or hyperphagic effects of stress in human beings; thus, the present study aimed to examine the impact of intranasal OT on snack intake with an emphasis on sweet snack intake in women after a stressful task.

In rats, a dose-dependent reduction in sucrose intake following OT administration has been shown to be dependent on activation of oxytocin receptors (OTR) in the ventral tegmental area (VTA Mullis, Kay, \& Williams, 2013). Activity of the VTA is known to influence palatable food consumption, reward, and various motivated behaviours (Lutter and Nestler, 2009) and it has been suggested that oxytocin may, therefore, alter the motivation to eat in the absence of hunger. OT knockout (KO) mice overconsume sweet-tasting sucrose and noncaloric saccharin but not lipid emulsions (Amico, Vollmer, Cai, Miedlar, \& Rinaman, 2005). The increased consumption of sucrose solution in OT KO mice is not altered by daily shaker platform stress (Billings, Spero, Vollmer, \& Amico, 2006), suggesting that sucrose hyperphagia in OT KO mice is independent of stress and activation of the HPA axis.

Furthermore, Sclafani et al. (2007) demonstrated, using isotonic carbohydrate solutions that varied in sweetness, that hyperphagia in OT KO mice could be extended to carbohydrate intake in general, but did not occur for a palatable, fat-rich emulsion (Intralipid): therefore OT brain pathways may contribute to carbohydrate-specific satiation, at least in rodents.

In humans, administration of 24 IU of intranasal oxytocin markedly decreased palatable snack intake in males 15 minutes after eating lunch compared to intranasal placebo administration (Burmester, 
Higgs, and Terry, 2018). The reductions in total snack intake were primarily driven by a $37 \%$ decline in sweet snack consumption, specifically chocolate cookie consumption, but a significant attenuation of salty cracker intake was also seen. In the same experiment, the intake of bland-tasting oatcakes was not affected by OT. A similar effect on sweet snack intake was found by Ott et al. (2013): twenty young male participants ate a buffet breakfast, then 1 hour 40 minutes later an OT-induced reduction of chocolate cookie intake (by 25\%) was found. These studies suggest that OT has anorectic properties and may form part of the homeostatic regulatory system of the hypothalamus, interacting with hormonal signals such as leptin and cholecystokinin (CCK) to inhibit food intake (Sabatier, Leng, \& Menzies, 2014). However, factors other than sufficient calorie intake appear to stimulate neuronal OT release coinciding with termination of feeding. These include meal onset (Sabatier et al., 2014), changes in blood osmolality as a result of increased salt intake (Stricker \& Verbalis, 1986), stomach distension (Calatayud, Quintana, Esplugues, \& Barrachina, 1999) and toxin ingestion (Olszewski, Waas, Brooks, Herisson, \& Levine, 2013). Together, this evidence suggests that OT may regulate palatable carbohydrate intake in a non-homeostatic manner, i.e. not dependent on normal satiation processes.

OT also interacts with other hormonal systems. The sex steroids, in particular the oestrogens, are important regulators of the OT system, resulting in a sex disparity in OT synthesis and receptor expression. Oestrogen receptors are expressed in hypothalamic OT neurons, and activation of these receptors enhances the anxiolytic effects of OT, suggesting a regulatory role for oestrogen in OT release. In addition, oestrogens influence the transcription of both OT and its receptors (McCarthy, McDonald, Brooks, \& Goldman, 1996; Olszewski et al., 2013; Young, Wang, Donaldson, \& Rissman, 1998). To a lesser extent, testosterone influences OT receptor expression, and its effects vary according to brain region (Insel, Young, Witt, \& Crews, 1993). Relatedly, sex hormones exert sexdependent stress effects that can lead to higher stress levels in women than men. Premenopausal women, for example, are vulnerable to monthly variations in oestrogen and progesterone that regulate central levels of serotonin and the progesterone metabolite, allopregnanolone, two endogenous “anxiolytics" (Li \& Graham, 2017). Taken together, the evidence suggests a bidirectional regulation 
between OT and oestrogen systems which may at least partially explain the sex-dependent effects of OT on certain behaviours (Carter, 2007; Choleris et al., 2003; Rilling et al., 2014).

Intracerebral OT given to rats that were exposed to emotional and physical stressors inhibited basal HPA axis activity but potentiated adrenocorticotropic hormone (ACTH) release under stress conditions, indicating a differential involvement of central OT on HPA axis functioning (Neumann, Krömer, Toschi, \& Ebner, 2000). This effect was reversible by OT receptor antagonism (Neumann, Torner, \& Wigger, 1999; Neumann, Wigger, Torner, Holsboer, \& Landgraf, 2000) clearly indicating an OT receptor-mediated effect. In a further experiment, both the tonic reductions in HPA axis activity induced by brain OT as well as on the stress-induced release of ACTH by intracerebral OT were shown to be sex independent (2000). In rat dams and women, lactation-related rises in OT reliably reduce ACTH and corticosterone/cortisol (Amico, Johnston, \& Vagnucci, 1994; Chiodera et al., 1991). Oxytocin and cortisol levels are bi-directionally interactive (Tops, Van Peer, Korf, Wijers, \& Tucker, 2007) and cortisol levels appear so tightly linked to oxytocin that cortisol measurement has been used as an experimental proxy for oxytocin (Meinlschmidt \& Heim, 2007). In previous studies showing OT's attenuation of palatable food intake, a concomitant decrease in cortisol was found after OT administration but not after placebo, perhaps indicating that a cortisol-mediated effect underlies OT's influence on palatable snack intake (Ott et al., 2013; Thienel et al., 2016).

In women with high cortisol reactivity to an acute stressor, greater stress-induced eating is observed (Epel, Lapidus, McEwen, \& Brownell, 2001), and although about equal numbers of the population overeat and undereat, as do neither (Wardle \& Gibson, 2016), there is a gender disparity, with women typically engaging in stress eating more frequently than men (Gibson, 2012). Eating energy-dense foods can relieve the negative consequences of stress and suppress the HPA axis (Buwalda, Blom, Koolhaas, \& van Dijk, 2001; Dallman et al., 2003; Foster et al., 2008; Pecoraro, Reyes, Gomez, Bhargava, \& Dallman, 2004). Eating in response to stress typically involves choosing highly palatable and energy-dense foods (Oliver, Wardle, \& Gibson, 2000; Pliner \& Mann, 2004) but the severity of the stressor may influence these patterns (Charmandari, Tsigos, \& Chrousos, 2005). Acute stressors can stimulate the sympathetic nervous system's 'fight or flight' activity to suppress appetite or can 
leave eating unchanged (Wardle \& Gibson, 2016). Chronic stress may have the opposite effect: for instance, chronically-stressed women who comfort eat have been shown to have a blunted cortisol response to an acute stressor (Tomiyama, Dallman, \& Epel, 2011). A suppressed cortisol response may also arise from the accumulation of visceral fat (Tomiyama et al., 2011), but using acute stressors such as public speaking and mathematical tasks, laboratory studies have produced robust stress-eating responses irrespective of BMI (Epel et al., 2001).

Given the prevalence of stress eating in women and the central elevation of OT by oestradiol, we would expect a sex difference with respect to the impact of OT administration on stress eating, with the inhibition of snack eating by OT likely to be enhanced in females. Here we investigate, for the first time, the effect of OT on stress-related snack intake that is not initiated by deprivation-induced hunger in women. To minimise the possibility that the effects of OT may be attributed to the modulation of such hunger-driven eating, participants were provided with lunch 20 minutes before a post-stress covert snack-eating test. Salivary cortisol was measured at frequent intervals for the first time in this OT and stress-eating experimental paradigm; furthermore, to avoid cortisol increases provoked by protein consumption (Gibson et al., 1999), the protein content of the preloaded food was kept below $10 \mathrm{~g}$.

\section{MATERIALS AND METHODS}

\subsection{Design}

A double-blind, placebo-controlled, randomised, and counterbalanced crossover protocol was implemented using a within-subjects design comprising drug or placebo tests scheduled about a week apart. The aims of the experiment were disguised to minimise undesirable impression management and participants were informed that the study investigated the effect of OT on stress and sensory perception. The study was approved by the Faculty Research Ethics Committee at Kingston University.

\subsection{Participants}


Thirty-eight healthy women aged between 19 and 51 years, $M(S D)=26.6(8.6)$ years were recruited both by word-of-mouth and in exchange for university course credits. Their body mass indices ranged from 18.4 to $35.0 \mathrm{~kg} / \mathrm{m}^{2}, M(S D)=24.8(4.2) \mathrm{kg} / \mathrm{m}^{2}$, indicating a range from low to obese. Although participants were not selected on the basis of their stress eating, we used a bespoke questionnaire that asked about a range of stress responses that included effects on eating, in order to disguise the experimental aims. The questionnaire asked participants to indicate how they react to a number of stress scenarios by rating their top three responses from the following options: "sleep", "disturbed sleep", “exercise”, “chat with someone”, "work/study", “eat", "reduced eating”, "smoke/vape”, "read/watch TV or film", "cry", "drink alcohol”, "let your hair down”, "drugs of abuse”, and "none of the options". Although all of the women demonstrated they were premenopausal by providing the date of their most recent menstrual cycle, at least three women (aged 46, 48 and 51 years) may have been perimenopausal due to their age. Participants with self-declared food allergies, diabetes, pregnant, breastfeeding, on prescription medicines or a vegan diet, were excluded. Altered endogenous OT function is associated with high emotional arousal or stress (e.g. bereavement, financial windfall) so participants reporting such events were also excluded (Engelmann, Ebner, Landgraf, Holsboer, \& Wotjak, 1999; Kovacs, 1986). Due to possible changes in taste sensitivity and suppressed eating (Audrain-McGovern \& Benowitz, 2011; Gromysz-Kalkowska, Wojcik, Szubartowska, \& Unkiewicz-Winiarczyk, 2002), regular smokers were also excluded. Participants were asked not to consume alcohol or non-steroidal anti-inflammatory drugs for 24 hours beforehand and to abstain from consuming food and sugary drinks for two hours before the experiment.

\subsection{Materials}

OT and vehicle were supplied by Victoria Pharmacy, Switzerland. Salter's electronic food scales were used to weigh food and Koogeek's biometric impedance scales were used to weigh participants and estimate fat ratio. Blood glucose levels were obtained using Accu-Chek's 'Aviv' hand-held monitor, the Omron handheld M2 model measured blood pressure, and Biopac's SC-Flex Pro was used with a fingertip sensor to measure heart rate. Saliva was collected in 'Salivettes' (Sarstedt UK, Leicester, England). The neutral film viewed by participants when waiting was David Attenborough's "Life of 
Plants".

Sham sensory tasks used the following: Elite Healthcare's 'Two Point Discriminator Touch-Test'; synthetic almond- and soap-scented smelling bottles (Bilendy Ltd, UK); and a stopwatch. Bespoke materials for the sham visual tasks were A4-sized laminated colour prints of famous paintings and A6sized laminated black-and-white pictures of castles for the "spot-the-difference" test. Music and Neuroimaging Laboratory's pitch discrimination test was taken online (Schlaug, 2017).

Self-report measures: Romantic involvement was estimated using Rubin's (1970) Romantic Love Scale. Self-monitoring behaviour was assessed using Synder's scale (1974) and anxiety was estimated with the trait scale of the State-Trait Anxiety inventory (STAI; Spielberger, Gorsuch, \& Lushene, 1970). The Dutch Eating Behaviour Questionnaire (DEBQ Van Strien, Frijters, Bergers, \& Defares, 1986) assesses levels of restrained (10 items), emotional (13 items), and external (10 items; one reversed) eating, with each scale having a range of mean scores from 1 to 5 ; a higher score reflects higher levels of the eating dimension.

Mood and appetite parameters were measured using a bespoke visual analogue scale (VAS) examining levels of happiness, excitement, fullness, thirst, anxiousness, and alertness with $100 \mathrm{~mm}$ lines anchored at "not at all" and "as much as I can imagine". For the taste test, VAS lines fixed by "not at all" and "as much as I can imagine" were presented to measure oatcake palatability, cracker saltiness, and chocolate cookie sweetness.

For the low-protein lunch, each participant was provided with a pre-packaged supermarket lunch (Waitrose 'Pesto and Spinach Salad', $376 \mathrm{kcal}, 190 \mathrm{~g}$ ). In the snack test, the three foods were chocolate cookies (Waitrose ‘Triple Chunk Chocolate Chip', 127 kcal, 25 g per unit, 450 g per bowl), TUC Classic Crackers (17 kcal, 5.4 g per unit, 230 g per bowl), and Sainsbury’s Oatcakes (47 kcal, $10.4 \mathrm{~g}$ per unit, $300 \mathrm{~g}$ per bowl). As per previous experiments, each snack-food type was matched for calorie content and macronutrients (see Burmester, Higgs, \& Terry, 2018, for full details) and presented in a separate bowl filled to the top, in order that substantial amounts could be eaten without the bowl appearing empty. 


\subsection{Procedure}

The timeline of events in a test session is shown in Table 1. After providing informed consent and confirming compliance with the inclusion and exclusion criteria, participants provided the first of two baseline saliva samples by drooling into the collection tube; at least $1 \mathrm{ml}$ was collected with each sample. Participants next completed the first of three mood VAS scales. Baseline blood pressure was taken as a biomarker of stress, and baseline blood glucose was then measured as OT affects postprandial glucose metabolism. Participant height, age, time since last meal, and content of last meal were recorded, and the second baseline cortisol sample was collected.

Next, the participant self-administered either 24 IU of OT or placebo, depending on session, under the supervision of the researcher, with six puffs alternated by nostril every 30 seconds; both the participant and the researcher were blind to the drug condition. Before participants were asked to eat the lunch provided, a measure of romantic love status (Rubin, 1970) was obtained in each session, because romantic attachment can influence OT's effects. Because thirst can sometimes be experienced as hunger (Balleine, 1994), participants were offered water and a maximum of $100 \mathrm{ml}$ was provided with their lunch; participants were also required to rinse out their mouths with a small sip of water after food to reduce salivary sample contamination.

To support the purpose of the study as it had been described to the participants, two sham sensory tasks were presented: a two-point discrimination touch test was conducted on the right index finger to identify the smallest interval, in millimetres, that could be sensed, and an olfactory test with smelling bottles containing synthetic soap or almond scents, depending on session, was then presented. Saliva was again drooled into the Salivettes and the participant's left hand was rested on the table top and a heart rate sensor placed on the middle finger. While keeping the hand still a 10-minute baseline recording was made while the participant watched a neutral film, at the end of which they were allowed to move their arm briefly and re-position it, if uncomfortable.

Stress was then induced by the participant being instructed to sing a song for a minute; heart rate recording was resumed (Brouwer \& Hogervorst, 2014). The participant was given no advice on song 
selection or style, and the researchers stopped all activity to create tension and watched the participant whose 60 seconds of singing was timed by stop-watch. At the end of the singing, the heart rate recording was paused, and the participant was instructed on the serial sevens task (Smith, 1967). Heart rate recording was resumed and a random starting number between 700 and 800 was given and the participant began 60 seconds of subtracting seven from the running total. Immediately following the second stress test, a saliva sample was taken, and blood pressure was measured.

Next, a taste test was conducted with the three snack foods. Small pieces of each snack, weighing about a gram, were provided for the participant to taste and rate on a VAS. Another mood/hunger VAS was then completed, and the sham pitch test was completed online. After the pitch test, another saliva sample was taken, followed by the first sham visual task, which involved presenting one of two nearidentical spot-the-difference pictures for 30 seconds. Then the critical snack test occurred: at $45-$ minutes post drug/placebo administration, the participant was instructed to enjoy a 10 minute 'cognitive break', let her mind 'relax', and select a preferred picture from a choice of five A4-sized prints of famous paintings. The experimenters announced that they would leave the room during the participant's 'cognitive break', and it was mentioned that the snack food would be thrown away after the experiment due to health and safety regulations, therefore they were free to help themselves to as much of the snack food as they wished. The snack test period lasted 10 mins, after which the second spot-the-difference picture was presented for 30 seconds, and the participant was asked to identify the difference between the two pictures.

After the break, the participant provided another saliva sample and completed a mood/hunger VAS. Next, the STAI was completed as a subjective measure of participant stress, then blood pressure and blood glucose were measured. One last saliva sample was provided. Finally, before participants left, they were asked whether they thought they had been given OT or placebo. At the end of the second visit, participant body mass was measured. Lunch and snack test foods were weighed before and after testing. Each session lasted about 95 mins; after the completion of the experiment, participants were emailed a link to complete an online survey comprising the DEBQ and Snyder's self-monitoring scale. 


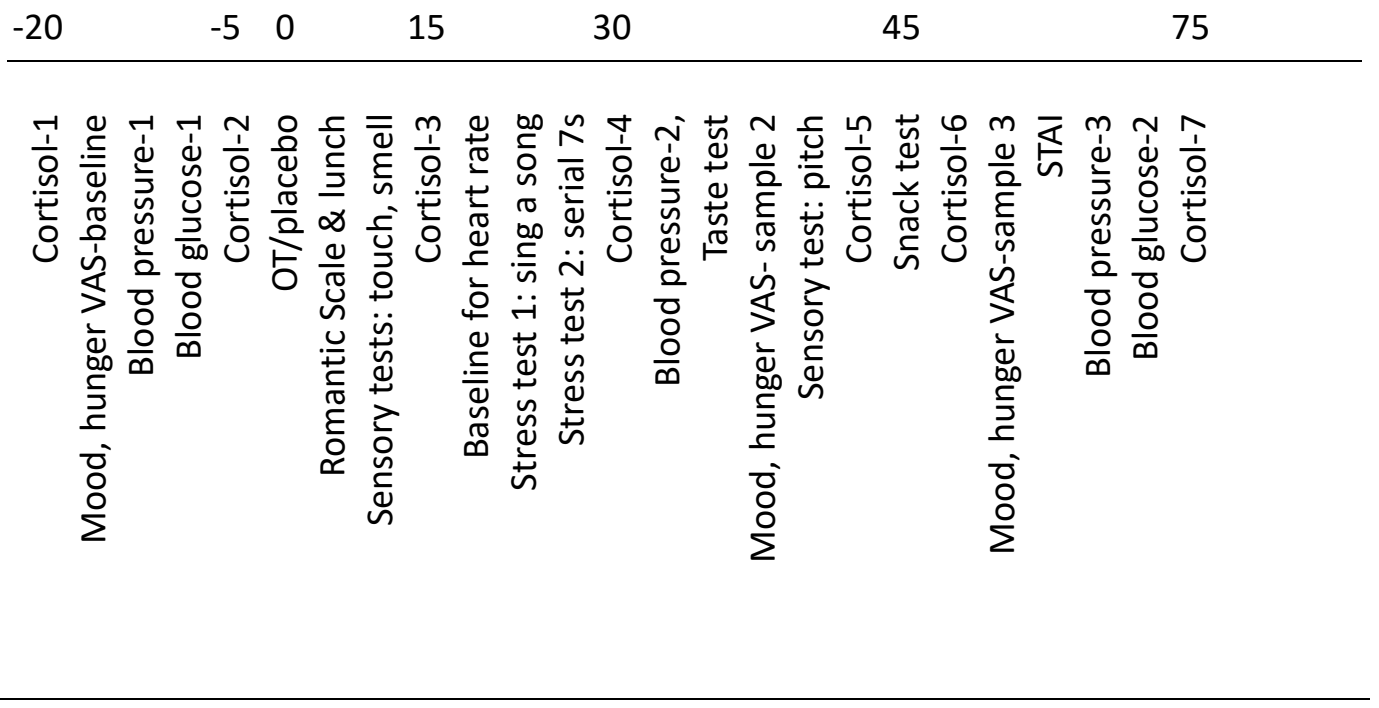

Table 1: Timeline of Experimental Session

Saliva assays for cortisol: Samples were centrifuged at $1000 \times \mathrm{g}$ for $2 \mathrm{~min}$, and supernatant was stored at $-20 \mathrm{C}$ for 1 to 6 days and then $-80 \mathrm{C}$ until assay. Saliva cortisol levels were measured all in the same day in duplicate by Surrey Assays Ltd by radioimmunoassay adapted from Riad-Fahmy et al. (1979). Limit of detection was $0.44+/-0.15 \mathrm{nmol} / \mathrm{L}$ and quality controls were low $=3.2+/-0.4 \mathrm{nmol} / \mathrm{L} \mathrm{CV}=$ $11.6 \%$; medium $=17.7+/-1.7 \mathrm{nmol} / \mathrm{L} \mathrm{CV}=9.6 \%$, and high $=48.2+/-3.2 \mathrm{nmol} / \mathrm{L} \mathrm{CV}=6.7 \%$.

\subsection{Data analysis}

Data were analysed using Statistical Package for the Social Sciences software (SPSS) version 25.

Stress eating status was determined from the bespoke questionnaire by a participant indicating that eating was a stress response to one or more of the six situations presented. To grade the stress eating, a count of the number of situations that triggered stress eating was made for participants who reported stress eating to give a score from 1 to 6 . Differences in chocolate cookie consumption, salty cracker consumption, oatcake consumption and snack food sensory taste tests for self-rated stress eaters and non-stress eaters were analysed using a mixed-measures analysis of variance for OT and placebo conditions. Taste sensitivity measures were also analysed using a repeated-measures analysis of 
variance (RMANOVA) for OT and placebo conditions. Baseline-adjusted scores were calculated for self-reported mood and appetite VAS by subtracting scores from the first VAS before administration of OT or placebo from scores on the second VAS and scores on the third VAS and analysed via $t$ tests and a 2 (Drug: OT or placebo) x 2 (Time: post stress or post stress +30') RMANOVA was conducted for each of the VAS items using baseline-adjusted change scores. The means of the two baseline cortisol samples (sample 1 and sample 2) were subtracted from each of the remaining samples within the same session (samples 3 to samples 7) to create baseline-adjusted data. Both area under the curve with respect to increase (AUCi) and a RMANOVA were used to compare baseline-adjusted cortisol scores for salivary cortisol levels of samples 3 to 7 taken at 15-, 30-, 45-, 60-, and 75-minutes post administration between drug conditions (Figure 4).

\section{RESULTS}

\subsection{Participant Characteristics}

For the dietary restraint component of the DEBQ, participants scored higher than the mean of normative scores $[M(S D)=2.75(0.79)]$ from the British validation of the DEBQ using healthy women (Wardle, 1987); $M(S D)=3.19(1.1)$. Participants scored slightly above a normative mean $[M$ $(S D)=3.19(1.1)]$ on the DEBQ external eating scale, $M(S D)=3.33(0.59)$, but at the low end of normative data $[M(S D)=2.65(0.72)]$ for emotional eating, $M(S D)=1.93(0.76)$. Scores on the selfmonitoring scale were below average, $M(S D)=8.89(2.65)$ and scores on the STAI (range from 0-80) were above normative averages [trait: $M=34.79, S D=9.22$ and state: $M=37.89, S D=9.90$ ] for both trait, $M(S D)=45.50(4.61)$ and state, $M(S D)=44.91(3.04)$ components. Scores on the romantic love scale were low-average $M(S D)=76.65$ (14.86) and were no different between placebo and oxytocin conditions: $t(37)=0.14, p=.89$.

Self-Rated Stress Eating Status: The DEBQ emotional eating scores for self-reported stress eaters $(M$ $=1.94, S D=.71)$ and non-stress eaters $(M=1.92, S D=.80)$ did not differ [one-way ANOVA, $F(1,26)$ $=0.006, p=.94]$. 


\subsection{Snack food intake}

There was no main effect of stress eating status on consumption of snack foods: $F(1,36)=0.14, p=$ .71. There was, however, a main effect of OT $\left[F(1,36)=12.38, p<.001\right.$, partial $\eta^{2}=.26$; see Figure 1], whereby significantly less snack food in total was eaten in the OT condition, $p=.001$, and this was not qualified by an interaction with stress eating status: $F(1,36)=2.57, p=.12$. The assumption of sphericity was violated for snack type $\left[\chi^{2}(2)=28.14, p<.001\right]$ and the interaction between snack type and drug $\left[\chi^{2}(2)=19.22, p<.001\right]$, so Greenhouse-Geisser adjustments were used: $\varepsilon=0.64$ for snack type, $\varepsilon=0.71$ for interaction. A main effect of snack type was found: $F(1.29,46.38)=24.75, p<.001$, partial $\eta^{2}=.41$. Post-hoc Bonferroni comparisons showed that significantly more of sweet (chocolate cookies) than salty (crackers) snacks were consumed $(p<.001)$, and significantly more of sweet than bland (oatcakes) snacks were eaten $(p<.001)$. There was no significant difference between salty and bland snack consumption $(p=.28)$; thus, overall participants ate more chocolate cookies than other snack types. There was no interaction between snack type and participants' self-rated stress eating status: $F(1.29,46.38)=0.60, p=.48$. There was, however, a significant interaction between drug condition and snack type $[F(1.41,50.61)=19.71, p=<.001]$, such that participants ate considerably less chocolate snack in the OT condition (Figure 1). The interaction between drug condition and snack type did not vary across the groups of stress eaters and non-stress eaters. 


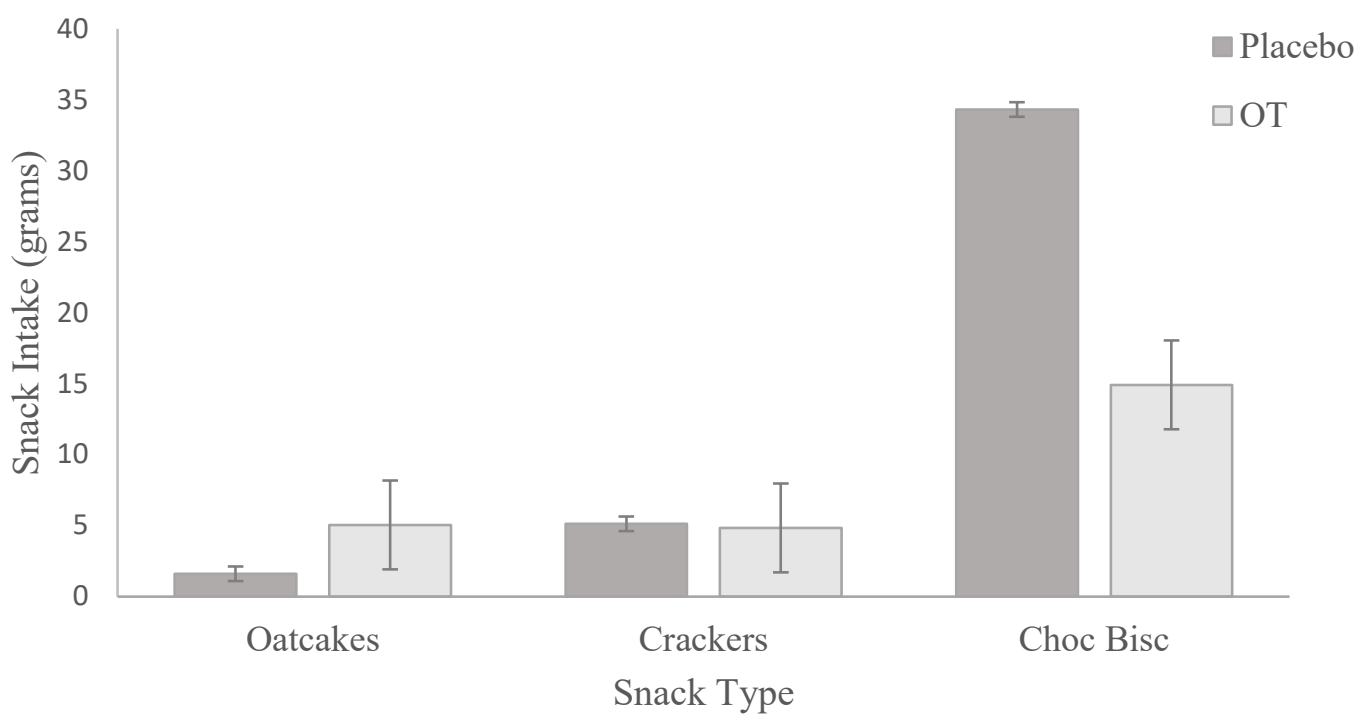

Figure 1: Effects of 24 IU oxytocin $(\mathrm{OT})$ vs. placebo on the intake (mean $\mathrm{g} \pm \mathrm{SEM} ; \mathrm{n}=38$ ) of three different snacks collapsed across stress eaters $(n=15)$ and non-stress eaters $(n=23)$. Choc Bisc $=$ chocolate chip cookies.

The drug by snack type interaction was further examined by post-hoc $t$ tests. There were no differences in snack consumption between stress eaters and non-stress eaters, so participants were analysed as a whole. OT significantly reduced the intake of chocolate cookies $[t(37)=5.10 p<.001]$ but not salty crackers $[t(37)=.262 p=.80]$ or oatcakes $[t(37)=1.18 p=.25]$. As expected, there was no significant difference between conditions on the consumption of lunch (a study requirement), $t(37)$ $=.74 p=.47$.

\subsection{Snack Food Sensory Taste Tests}

OT tended to reduce the reported sweetness of the chocolate cookies for stress eaters but tended to increase rated sweetness for non-stress eaters [Figure 2: drug x stress eating interaction, $F(1,36)=$ $4.36, p=.04$, partial $\left.\eta^{2}=.11\right]$. There were no main effects for drug or stress eating on sweetness rating 
$(F \mathrm{~s}<1)$ : overall mean sweetness ratings for chocolate cookies were $77.50 \mathrm{~mm}(S D=12.76)$ in the placebo condition and $77.76 \mathrm{~mm}(S D=13.50)$ after OT, i.e. did not differ, $t(37)=0.11 p=.91$.

The mean saltiness ratings for crackers were similar in both the placebo $(55.79 \mathrm{~mm}, S D=19.52 \mathrm{~mm})$ and oxytocin conditions ( $56.26 \mathrm{~mm}, S D=17.41 \mathrm{~mm}), t(37)=0.17 p=.87$. However, self-reported stress eaters rated crackers as significantly saltier than did non-stress eaters, irrespective of drug [Figure 3: stress eater status main effect, $F(1,36)=5.16, p=.029$, partial $\eta^{2}=.13$ ]. The drug effect and interaction effect were not significant $(F \mathrm{~s}<1)$.

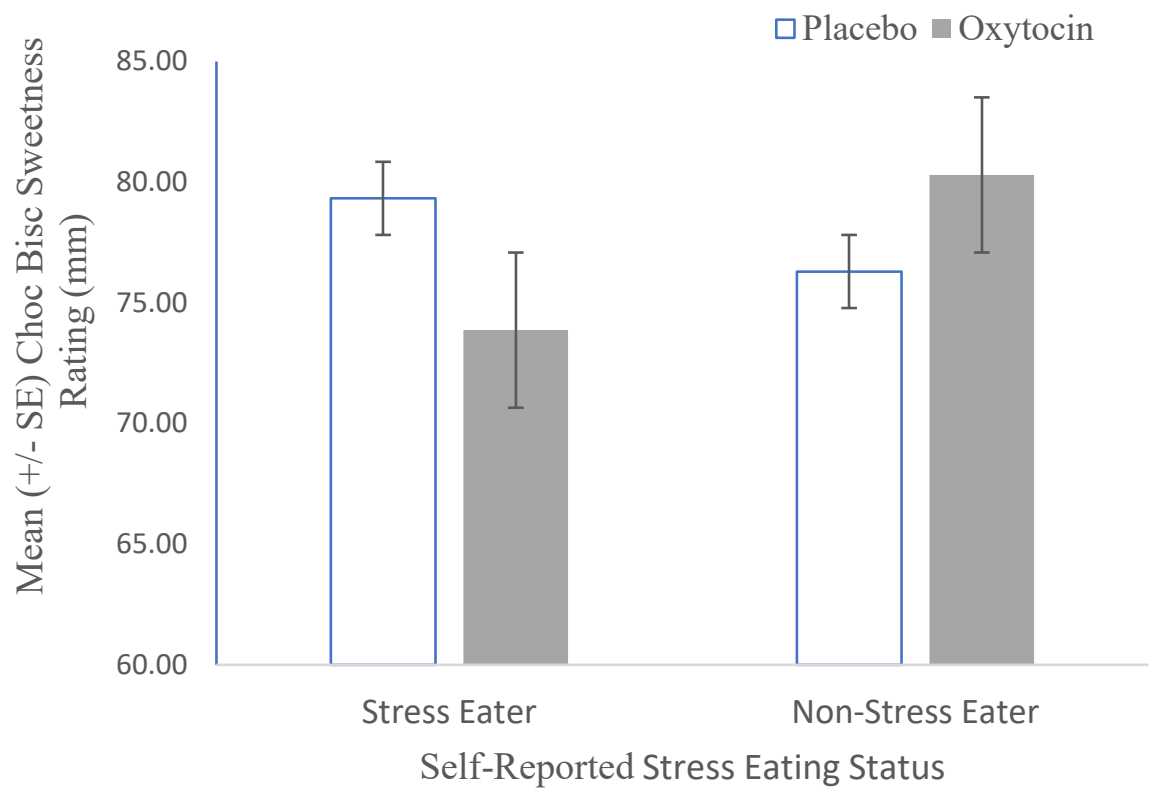

Figure 2: Interaction of drug (oxytocin vs placebo) and stress eating status (stress eater $[n=15]$ vs nonstress eater [ $\mathrm{n}=23]$ ) on rated sweetness of chocolate cookies. Choc bisc $=$ chocolate chip cookies. 


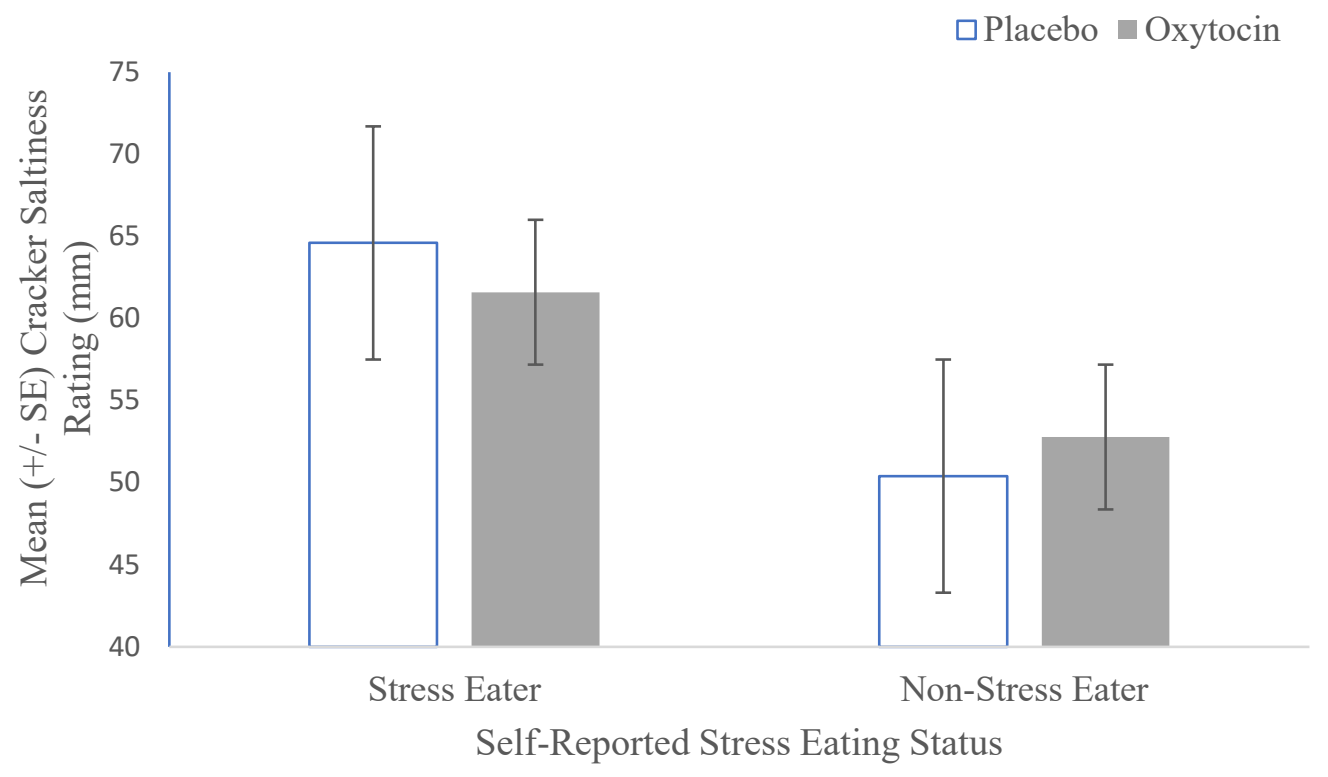

Figure 3: Interaction of drug (oxytocin vs placebo) and stress eating status (stress eater [ $\mathrm{n}=15]$ vs nonstress eater $[\mathrm{n}=23])$ on rated saltiness of crackers.

Oatcakes were rated similarly for palatability in the placebo condition $(M=34.92 \mathrm{~mm}, S D=22.46$ $\mathrm{mm})$ as in the oxytocin condition $(M=37.63 \mathrm{~mm}, S D=26.53 \mathrm{~mm}) t(37)=0.62 p=.54$, and palatability ratings did not differ between stress eating groups $\left(F_{\mathrm{S}}<1.1\right)$.

\subsection{Self-reported mood and appetite VAS}

Overall, there were no significant differences between drug conditions for changes in alertness, anxiety, happiness, excitement, fullness or thirst. However, over the course of the placebo session there was a significant decline in ratings of happiness $[t(37)=2.17 p=.037]$, excitement $[t(37)=$ $2.85 p=0.07]$, and alertness $[t(37)=2.62 p=.013]$, whereas in the OT session, participant ratings of happiness, excitement, and alertness did not change significantly (Table 2). 


\begin{tabular}{|c|c|c|c|c|c|}
\hline \multirow[t]{2}{*}{ VAS item } & \multirow[t]{2}{*}{ Time point } & \multicolumn{2}{|c|}{ Placebo } & \multicolumn{2}{|l|}{ OT } \\
\hline & & M & $\mathrm{SD}$ & M & $\mathrm{SD}$ \\
\hline \multirow[t]{3}{*}{ Alert } & Baseline & 51.50 & 23.13 & 53.39 & 23.61 \\
\hline & Post-stress & 49.58 & 22.45 & 47.74 & 24.38 \\
\hline & Post-stress +30 & 42.58 & 23.14 & 48.87 & 22.81 \\
\hline \multirow[t]{3}{*}{ Anxious } & Baseline & 20.74 & 20.38 & 22.21 & 22.87 \\
\hline & Post-stress & 19.34 & 18.70 & 17.21 & 16.97 \\
\hline & Post-stress +30 & 18.68 & 18.94 & 17.87 & 15.68 \\
\hline \multirow[t]{3}{*}{ Excited } & Baseline & 36.32 & 19.76 & 38.21 & 22.49 \\
\hline & Post-stress & 38.71 & 24.38 & 37.55 & 22.08 \\
\hline & Post-stress $+30^{\prime}$ & 31.76 & 19.77 & 35.45 & 23.36 \\
\hline \multirow[t]{3}{*}{ Full } & Baseline & 23.45 & 19.78 & 31.92 & 24.59 \\
\hline & Post-stress & 60.39 & 22.59 & 60.71 & 20.44 \\
\hline & Post-stress $+30^{\prime}$ & 64.53 & 22.45 & 64.84 & 23.30 \\
\hline \multirow[t]{3}{*}{ Happy } & Baseline & 58.68 & 18.11 & 56.29 & 21.12 \\
\hline & Post-stress & 62.89 & 16.06 & 57.29 & 19.02 \\
\hline & Post-stress +30 & 58.18 & 18.86 & 58.24 & 19.83 \\
\hline Thirsty & Baseline & 56.45 & 27.44 & 56.16 & 24.84 \\
\hline
\end{tabular}




$\begin{array}{lllll}\text { Post-stress } & 68.47 & 20.64 & 59.29 & 23.23 \\ & & & & \\ \text { Post-stress+30, } & 68.18 & 22.76 & 66.58 & 24.88\end{array}$

Table 2: Mean (SD) 100-mm VAS mood and appetite ratings for oxytocin (OT) and placebo conditions over baseline and post-stress time points $(n=38)$

There was no main effect of drug condition $[F(1,37) 0.23, p=.89]$ or sample time $[F(1,37) 1.84, p=$ .12] for the "happiness" item but there was a significant interaction between drug and sample time $\left[F(1,37) 5.13, p=.029\right.$, partial $\left.\eta^{2}=.12\right]$ such that self-rated happiness declined from a slight rise immediately post-stress to the end of the session in the placebo condition but it did not drop in the oxytocin condition. There were no further main effects or interactions for the remaining VAS items, except that self-rated "excitement" decreased significantly by the last measure in both drug conditions $\left[F(1,37)=9.07, p=.005\right.$, partial $\left.\eta^{2}=.20\right]$ and ratings of fullness increased significantly through both sessions $\left[F(1,37)=6.80, p=.013\right.$, partial $\left.\eta^{2}=.15\right]$.

\subsection{Cortisol}

Oxytocin did not significantly change cortisol levels $[F(1,37)=.85, p=.36]$. Mauchly's test indicated that the assumption of sphericity had been violated for the sample time factor $\left[\chi^{2}(9)=72.00, p<.001\right]$ and the interaction between sample and drug $\left[\chi^{2}(9)=36.29, p<.001\right]$, so degrees of freedom were estimated using the Greenhouse-Geisser estimates of sphericity ( $\varepsilon=0.50$ for sample, $\varepsilon=0.65$ for interaction). As expected, there was a main effect of sample time with salivary cortisol quantities dropping over time $\left[F(2.0,74.1)=7.76, p=.001\right.$, partial $\left.\eta^{2}=.10\right]$ but there was no interaction with $\operatorname{drug}[F(2.6,96.0)=0.82, p=.47]$.

No significant differences between drug conditions were seen in a repeated-measures ANOVA using the AUCi of baseline-adjusted cortisol, $F(1,37) 0.74, p=.40$. Paired $t$ tests on peak cortisol were not significantly different between conditions using baseline-adjusted data, $t(37)=.74, p=.47$, and $t$ tests on the baseline-adjusted final samples (60 and 75 minutes) were also not significantly different. 
Finally, there was no significant correlation between AUCi measures and chocolate cookie snack intake, $r=-.01$.

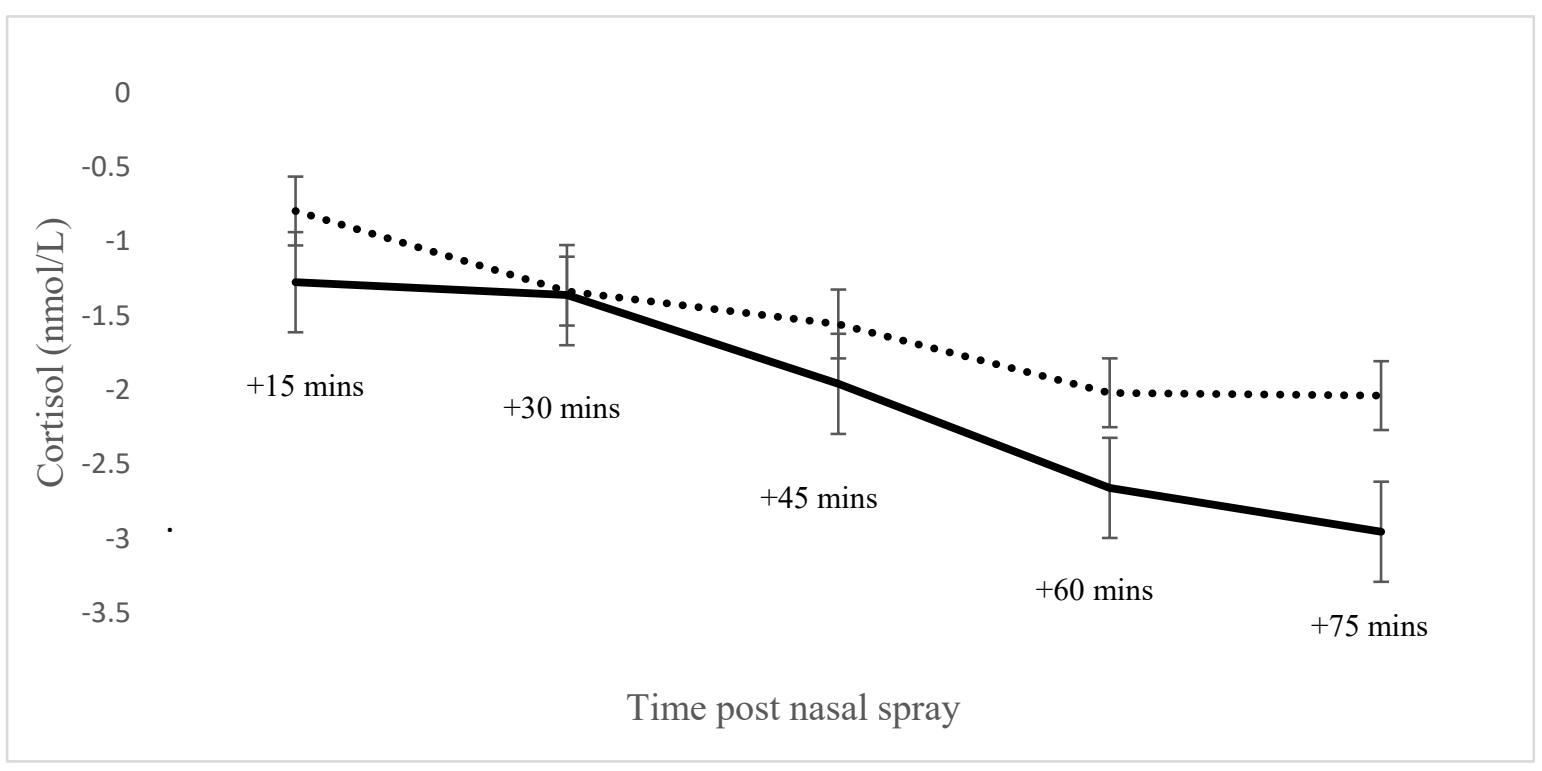

Figure 4: Baseline-adjusted salivary cortisol concentration (nmol/L; mean \pm SEM) at 15-, 30-, 45-, 60-, and 75-minutes post administration in the oxytocin (solid line) and placebo (dotted line) conditions.

\subsection{Blood glucose, blood pressure and heart rate}

A 2 (drug: OT and placebo) x 2 (Sample: first and second) repeated-measures ANOVA was used to analyse blood glucose samples. There was no main effect of drug on blood glucose levels $F(1,37)=$ $0.28, p=.60$. There was, however, a main effect of sample time $\left[F(1,37)=83.95, p<.001\right.$, partial $\eta^{2}$ $=.69]$ with samples taken after eating being significantly higher than before eating. There was no interaction between blood sample time and drug condition $F(1,37)=0.00, p=.98$.

A repeated-measures ANOVA assessed the effect of OT and the stress task on blood pressure.

Baseline blood pressure readings taken 10 minutes before administration of drug and stress tests were subtracted from the readings taken before and after the snack test to form baseline-adjusted change data (Table 3). 


\begin{tabular}{|c|c|c|c|c|c|}
\hline & & \multicolumn{2}{|c|}{ Systolic } & \multicolumn{2}{|c|}{ Diastolic } \\
\hline & & M & $\mathrm{SD}$ & M & $\mathrm{SD}$ \\
\hline \multirow[t]{2}{*}{ OT } & Before Stress & 0.50 & 7.74 & -0.66 & 5.43 \\
\hline & After Stress & -1.03 & 7.32 & -1.26 & 5.72 \\
\hline \multirow[t]{2}{*}{ Placebo } & Before Stress & 1.21 & 6.61 & -1.89 & 7.27 \\
\hline & After Stress & -0.11 & 6.25 & -1.95 & 6.67 \\
\hline
\end{tabular}

Table 3: Mean (SD) Baseline-Adjusted Measurements in Systolic and Diastolic Blood Pressure after oxytocin $(\mathrm{OT})$ or Placebo $(\mathrm{mmHg} ; \mathrm{n}=38)$

There were no main effects of OT on either systolic $[F(1,37)=0.31, p=.58]$ or diastolic $[F(1,37)=$ $0.58, p=.45]$ blood pressure. Neither systolic $[F(1,37)=3.36, p=.08]$ nor diastolic blood pressure $[F(1,37)=0.23, p=.63]$ changed between pre- and post-stress phases during the sessions

Due to equipment error, the heart-rate data from 16 participants was not analysable. The heart-rate data for the remaining 23 participants was analysed by a 2 (drug: oxytocin and placebo) $\mathrm{x} 2$ (sample: first and second) repeated-measures ANOVA to assess the effect of oxytocin on heart rate. Baseline heart-rate data measured in beats per minute (BPM) was recorded for 10 minutes, then trimmed by the first and last two minutes to create a reliable baseline rate. Mean $( \pm S D)$ heart-rate readings in the baseline placebo condition $[82.79 \pm 19.12 \mathrm{bpm}]$ were below mean $( \pm S D)$ readings obtained during the sing-a-song stress test $[95.60 \pm 15.57 \mathrm{bpm}]$. The same pattern was observed in the oxytocin sessions, where mean $( \pm S D)$ heart-rate readings at baseline $[82.38 \pm 8.98 \mathrm{bpm}]$ were below mean $( \pm$ $S D$ ) readings obtained during the sing-a-song stress test [99.91 $\pm 17.33 \mathrm{bpm}]$. ANOVA showed no main effect of drug $[F(1,22)=0.37, p=.55]$, but heart rate increased significantly in the sing-a-song 
test period with a large effect: $F(1,22)=29.13, p<.001$, partial $\eta^{2}=.57$; no interactions emerged.

To ensure that increases in heart rate during the Sing-a-Song stress test were not due to the physiological effects of singing, the anticipatory phase was calculated from 5 to 20 seconds after the researcher's instructions and separated from the test phase, which was calculated from the end of the recording backwards for 20 seconds. Results were examined via a $t$ test and the mean increase in heart rate during the anticipatory phase $(M=15.64, S D=3.26)$ was slightly higher than the mean heart rate increase during the singing stress test $(M=15.75, S D=3.28)$, but there were no statistically significant differences, $t(22)=1.62, p=.12$. These results indicate that the rise in heart rate during the Sing-a-Song stress test was not driven solely by the physiological impact of singing.

\section{DISCUSSION}

This study demonstrated for the first time that intranasal administration of 24 IU of OT to women significantly reduced postprandial intake of sweet snack foods after stressful tasks, regardless of their status as stress eaters or non-stress eaters. Unlike previous studies in men (Ott et al., 2013), OT had no significant effect on cortisol levels, suggesting that OT's attenuation of palatable snacking in the absence of hunger is not driven by OT's suppressive effect on the HPA axis. This is the first study to show that OT reduces eating in women, and unlike the previous study by Burmester, Higgs and Terry (2018) in males, no reductions were seen on salty snack intake. Self-reported levels of happiness, excitement, and alertness declined significantly in the placebo condition but remained stable in the OT condition, indicating that OT positively affected mood and arousal by preventing a decline over the course of the session. In contrast to previous studies (Ott et al., 2013; e.g. Petersson, 2002b; UvnasMoberg, 1997), OT did not affect blood glucose or blood pressure; it is likely that procedural differences account for this. Heart rate was significantly elevated after the stress tests but not affected by OT ; it might be that a more nuanced analysis of cardiac response - such as heart rate variability might reveal differences (Petersson, 2002a), but since the primary purpose of the heart rate recording was to establish that the stress tests were effective, this was not undertaken. 
The magnitude of OT's inhibition of chocolate cookie snack intake in this female-only sample is comparable to that reported in our earlier study that tested men (Burmester et al., 2018): consumption dropped by $43 \%$ in females and $37 \%$ in males. On the other hand, the German research groups of Ott and Thienel saw reductions of only $25 \%$ in normal weight men and $19.5 \%$ in obese men, following a similar bogus taste test (Ott et al., 2013; Thienel et al., 2016). The Ott group tested participants on a wide array of eating-related measures, but the only significant effect of OT on intake was with chocolate cookies, in line with this study as well as our earlier one (Burmester et al., 2018). Participants in the German studies fasted for 14.5 hours, then ate breakfast from a buffet, before being tested on snack eating 100 minutes after that. It is possible, therefore, that gastric emptying might have played a role in triggering snack eating for the German studies' participants, especially given that many of the high-calorie items from the buffet were liquids (e.g. strawberry milk, vanilla pudding, juices, honey, etc.). The neural mechanisms underlying OT's anorectic capacity are complex but involve motivational and physiological changes (for a review, see Sabatier et al., 2014). It might be the case that the difference in the magnitude of OT's effect across experiments reflects its differential modulation of palatable food intake in the presence of deprivation-induced hunger versus palatable food intake that is not initiated by such mechanisms.

Although female oestradiol levels vary across the menstrual cycle, in this experiment we did not control for menstrual phase or hormone-based contraceptive usage specifically. However, the possibility of hormone suppression by contraceptives was minimised because participants taking prescribed medicines were excluded and all participants provided the date of their last menstrual cycle. Menstrual phase was not controlled for at testing, so differences in oestrogen levels may have added variance to oxytocin activity, potentially reducing effect sizes in our results. Nevertheless, reductions in palatable snack intake have been observed across different menstrual phases, suggesting that oestrogen-related interactions did not drive attenuation of palatable snack intake (Asarian \& Geary, 2006; Buffenstein, Poppitt, McDevitt, \& Prentice, 1995). Further, oestradiol increases OT levels but menstrual peaks of oestradiol result in increased appetite and food intake, rather than the expected reductions that OT might bring about. It is possible that an exogenous OT boost has a 
different effect from endogenous rises of OT, which may explain how the data here are unaffected by menstrual fluctuations, but further research is required. Aulinas et al. (2018) distinguish between the patterns of postprandial peripheral OT release, which remain stable across menstrual phases, and fasting levels of peripheral OT recorded before food intake, which vary, to explain the discrepancy. However, previous studies rely on peripheral and central OT measurements, which are not tightly correlated, so further research is needed to elucidate the effects of oestrogen on central levels of OT (Mccullough, Churchland, \& Mendez, 2013).

Stress can preferentially increase consumption of sweet, fatty food (O'Connor, Jones, Conner, McMillan, \& Ferguson, 2008; Oliver et al., 2000), which may account for salty food intake not changing after OT in this experiment unlike for our previous male experiment (Burmester, Higgs, and Terry, 2018). In mice, OT reduces consumption of sweet-tasting food including saccharin (Billings et al., 2006), whereas OT KO mice overconsume sweet solutions (Amico et al., 2005; Sclafani et al., 2007). Animal research has suggested that oxytocin's anorectic effects are mediated by VTA changes that dampen reward (Mullis, Kay, \& Williams, 2013). Here, reductions in sweet-snack eating after oxytocin coincided with reductions in sweet-taste sensitivity, suggesting that oxytocin's alteration of sweet sensitivity may also contribute to the attenuation of intake. Although the reduction in sweetness rating was only apparent in stress eaters, that group could be expected to be expressing more appetite for the chocolate cookies after stress compared to non-stress eaters (van Strien, Gibson, Baňos, Cebolla \& Winkens, 2019), and indeed sweetness ratings were slightly higher on average for stress eaters under placebo conditions. Oxytocin's reduction of sweetness sensitivity is in line with rodent studies but not with previous human research indicating that oxytocin does not significantly affect taste ratings (Ott et al., 2013; Thienel et al., 2016). The different hunger status of participants in this study and the Ott and Thienel studies may account for this variability. The addition of acute stress promotes sweet food preference as sweet food reduces HPA axis activity (Pecoraro, Reyes, Gomez, Bhargava, \& Dallman, 2004), so it is possible that oxytocin's reduction of sweet-taste perception is specific to a stress paradigm.

In this experiment, a typical circadian reduction of cortisol levels over time was observed. In contrast, 
Ott et al. (2013) and Thienel et al. (2016) saw cortisol levels rise after placebo and oxytocin administration following a free-choice breakfast buffet, although they were significantly lower in the OT condition at 45 minute and two hours post-administration. It is likely that the relatively high protein intake (36 g) from their breakfast buffet induced a metabolic processing rise in cortisol (Gibson et al., 1999), which was avoided in our study by restricting the protein content of the lunch; this could also be related to the reduced postprandial glucose rise after OT treatment (Ott et al., 2013). There may be alternative mechanisms through which OT acts to reduce stress eating, such as the reward system or the suppression of amygdala activity (Bale, Davis, Auger, Dorsa, \& McCarthy, 2001; Huber, Veinante, \& Stoop, 2005).

Nevertheless, Ott et al. (2013) reported that the OT-induced suppression in cortisol (AUC) correlated with the reduction in chocolate cookie intake, suggesting a mechanistic link. However, oxytocin's regulation of the HPA axis is context-dependent in rats, where oxytocin attenuates tonic HPA activity but not stress-induced (phasic) HPA activity. The serial sevens subtraction stressor employed here is widely used to trigger a stress-related cortisol response (Gotlib, Joormann, Minor, \& Hallmayer, 2008), so oxytocin's effects may have a similar tonic-only effect in humans. The measurement of cortisol may also explain the differences between these findings and previous studies. The Gotlib, Ott and Thienel groups examined total plasma cortisol, only a small percentage of which is active and that is known to be affected by dietary protein intake (Anderson, Rosner, Khan, New, Pang, Wissel, \& Kappas, 1987) (Gibson et al., 1999), whereas in this study the more active form of salivary cortisol was collected. Another possibility is that males and females react differently to exogenous oxytocin.

As a natural reward, food intake - particularly of sugar - activates many of the same brain areas that are engaged by drugs of abuse (Berridge, 1996). OT has extensive effects on substance use, typically reducing intake and suppressing withdrawal effects and cravings for a range of substances that activate central reward circuits (such as the mesolimbic dopaminergic system; Bailey, 2014; McGregor \& Bowen, 2012; Zanos et al., 2014; Zanos et al., 2018). The reduction in non-hunger initiated palatable food intake induced by OT might, therefore, be mediated to some degree by a dampening of palatable food-induced limbic reward system activation (Bowen \& Neumann, 2017; 
Hernandez \& Hoebel, 1988; Long, Blundell, \& Finlayson, 2015; Volkow et al., 2010), which would also be compatible with a reduction in sweetness ratings specifically by participants who are prone to affect-driven stress eating.

To conclude, for the first time, we have shown that oxytocin reduces postprandial snacking of palatable sweet cookies in females without concomitant reductions in salivary cortisol. The study did not measure oestrogen levels or control for menstrual fluctuations, and this would be a useful future research direction. The findings suggest that the inhibitory effects of OT on stress-induced palatable food intake may not be mediated by the HPA axis, and that OT may reduce palatable food reward in women. OT may, therefore, potentially contribute towards tackling "comfort eating" and the concomitant obesity that can arise as a consequence, and these findings provide further support for future research into OT's potential as a novel therapeutic agent for obesity and disordered eating. 


\section{REFERENCES}

Amico, J. A., Johnston, J. M., \& Vagnucci, A. H. (1994). Suckling-induced attenuation of plasma cortisol concentrations in postpartum lactating women. Endocrine Research, 20(1), 79-87.

Amico, J. A., Vollmer, R. R., Cai, H. M., Miedlar, J. A., \& Rinaman, L. (2005). Enhanced initial and sustained intake of sucrose solution in mice with an oxytocin gene deletion. American Journal of Physiology.Regulatory, Integrative and Comparative Physiology, 289(6), R1798-806. doi:00558.2005 [pii]

Asarian, L., \& Geary, N. (2006). Modulation of appetite by gonadal steroid hormones. Philosophical Transactions of the Royal Society of London. Series B, Biological Sciences, 361(1471), 12511263. doi:92V608472P85094J [pii]

Audrain-McGovern, J., \& Benowitz, N. (2011). Cigarette smoking, nicotine, and body weight. Clinical Pharmacology \& Therapeutics, 90(1), 164-168.

Aulinas, A., Pulumo, R. L., Elisa, A., Mancuso, C., Christopher, J., Meghan, S., . . Eddy, K. T. (2018). Endogenous oxytocin levels in relation to food intake, menstrual phase, and age in females. The Journal of Clinical Endocrinology \& Metabolism,

Bailey, A. (2014). A randomised double blind placebo controlled pilot trial of oxytocin efficacy in treating detoxified opioid dependent individuals. Retrieved from https://www.clinicaltrialsregister.eu/ctr-search/search?query=2014-002708-26

Bale, T. L., Davis, A. M., Auger, A. P., Dorsa, D. M., \& McCarthy, M. M. (2001). CNS regionspecific oxytocin receptor expression: Importance in regulation of anxiety and sex behavior. The Journal of Neuroscience : The Official Journal of the Society for Neuroscience, 21(7), 25462552. doi:21/7/2546 [pii] 
Balleine, B. (1994). Asymmetrical interactions between thirst and hunger in pavlovian-instrumental transfer. The Quarterly Journal of Experimental Psychology, 47(2), 211-231.

Berridge, K. C. (1996). Food reward: Brain substrates of wanting and liking. Neuroscience \& Biobehavioral Reviews, 20(1), 1-25.

Billings, L. B., Spero, J. A., Vollmer, R. R., \& Amico, J. A. (2006). Oxytocin null mice ingest enhanced amounts of sweet solutions during light and dark cycles and during repeated shaker stress. Behavioural Brain Research, 171(1), 134-141.

Bowen, M. T., \& Neumann, I. D. (2017). Rebalancing the addicted brain: Oxytocin interference with the neural substrates of addiction. Trends in Neurosciences,

Brouwer, A. M., \& Hogervorst, M. A. (2014). A new paradigm to induce mental stress: The sing-asong stress test (SSST). Frontiers in Neuroscience, 8, 224. doi:10.3389/fnins.2014.00224 [doi]

Buffenstein, R., Poppitt, S. D., McDevitt, R. M., \& Prentice, A. M. (1995). Food intake and the menstrual cycle: A retrospective analysis, with implications for appetite research. Physiology \& Behavior, 58(6), 1067-1077.

Burmester, V., Higgs, S., \& Terry, P. (2018). Rapid-onset anorectic effects of intranasal oxytocin in young men. Appetite,

Buwalda, B., Blom, W. A., Koolhaas, J. M., \& van Dijk, G. (2001). Behavioral and physiological responses to stress are affected by high-fat feeding in male rats. Physiology \& Behavior, 73(3), $371-377$

Calatayud, S., Quintana, E., Esplugues, J., \& Barrachina, M. D. (1999). Role of central oxytocin in the inhibition by endotoxin of distension-stimulated gastric acid secretion. Naunyn-Schmiedeberg's Archives of Pharmacology, 360(6), 676-682. 
Cardoso, C., Ellenbogen, M. A., Orlando, M. A., Bacon, S. L., \& Joober, R. (2013). Intranasal oxytocin attenuates the cortisol response to physical stress: A dose-response study. Psychoneuroendocrinology, 38(3), 399-407.

Carter, C. S. (2007). Sex differences in oxytocin and vasopressin: Implications for autism spectrum disorders? Behavioural Brain Research, 176(1), 170-186.

Carter, C. S., \& Altemus, M. (1997). Integrative functions of lactational hormones in social behavior and stress managementa. Annals of the New York Academy of Sciences, 807(1), 164-174.

Charmandari, E., Tsigos, C., \& Chrousos, G. (2005). Endocrinology of the stress response. Annu.Rev.Physiol., 67, 259-284.

Chiodera, P., Salvarani, C., Bacchi-Modena, A., Spallanzani, R., Cigarini, C., Alboni, A., . . Coiro, V. (1991). Relationship between plasma profiles of oxytocin and adrenocorticotropic hormone during suckling or breast stimulation in women. Hormone Research, 35(3-4), 119-123. doi:10.1159/000181886 [doi]

Choleris, E., Gustafsson, J. A., Korach, K. S., Muglia, L. J., Pfaff, D. W., \& Ogawa, S. (2003). An estrogen-dependent four-gene micronet regulating social recognition: A study with oxytocin and estrogen receptor-alpha and -beta knockout mice. Proceedings of the National Academy of Sciences of the United States of America, 100(10), 6192-6197. doi:10.1073/pnas.0631699100 [doi]

Dallman, M. F., Pecoraro, N., Akana, S. F., La Fleur, S. E., Gomez, F., Houshyar, H., . . Manalo, S. (2003). Chronic stress and obesity: A new view of "comfort food". Proceedings of the National Academy of Sciences of the United States of America, 100(20), 11696-11701. doi:10.1073/pnas.1934666100 [doi] 
Engelmann, M., Ebner, K., Landgraf, R., Holsboer, F., \& Wotjak, C. (1999). Emotional stress triggers intrahypothalamic but not peripheral release of oxytocin in male rats. Journal of Neuroendocrinology, 11, 867-872.

Epel, E., Lapidus, R., McEwen, B., \& Brownell, K. (2001). Stress may add bite to appetite in women: A laboratory study of stress-induced cortisol and eating behavior. Psychoneuroendocrinology, 26(1), 37-49.

Foster, M. T., Warne, J. P., Ginsberg, A. B., Horneman, H. F., Pecoraro, N. C., Akana, S. F., \& Dallman, M. F. (2008). Palatable foods, stress, and energy stores sculpt corticotropin-releasing factor, adrenocorticotropin, and corticosterone concentrations after restraint. Endocrinology, $150(5), 2325-2333$.

Gibson, E. L., Checkley, S., Papadopoulos, A., Poon, L., Daley, S., \& Wardle, J. (1999). Increased salivary cortisol reliably induced by a protein-rich midday meal. Psychosomatic Medicine, 61(2), 214-224.

Gibson, E. L. (2012). The psychobiology of comfort eating: Implications for neuropharmacological interventions. Behavioural Pharmacology, 23(5-6), 442-460. doi:10.1097/FBP.0b013e328357bd4e [doi]

Gotlib, I. H., Joormann, J., Minor, K. L., \& Hallmayer, J. (2008). HPA axis reactivity: A mechanism underlying the associations among 5-HTTLPR, stress, and depression. Biological Psychiatry, 63(9), 847-851.

Gromysz-Kalkowska, K., Wojcik, K., Szubartowska, E., \& Unkiewicz-Winiarczyk, A. (2002). Taste perception of cigarette smokers. Annales Universitatis Mariae Curie-Sklodowska.Sectio D: Medicina, 57(2), 143-154.

Hernandez, L., \& Hoebel, B. G. (1988). Food reward and cocaine increase extracellular dopamine in the nucleus accumbens as measured by microdialysis. Life Sciences, 42(18), 1705-1712. 
Huber, D., Veinante, P., \& Stoop, R. (2005). Vasopressin and oxytocin excite distinct neuronal populations in the central amygdala. Science (New York, N.Y.), 308(5719), 245-248. doi:308/5719/245 [pii]

Insel, T. R., Young, L. J., Witt, D. M., \& Crews, D. (1993). Gonadal steroids have paradoxical effects on brain oxytocin receptors. Journal of Neuroendocrinology, 5(6), 619-628.

Jones, C., Barrera, I., Brothers, S., Ring, R., \& Wahlestedt, C. (2017). Oxytocin and social functioning. Dialogues in Clinical Neuroscience, 19(2), 193-201.

Kovacs, G. (1986). Oxytocin and behavior. Neurobiology of oxytocin (pp. 91-128) Springer.

Leng, G., \& Sabatier, N. (2017). Oxytocin-the sweet hormone? Trends in Endocrinology \& Metabolism, 28(5), 365-376.

Leslie, M., Silva, P., Paloyelis, Y., Blevins, J. E., \& Treasure, J. (2018). A systematic review and quantitative Meta-Analysis of oxytocin's effects on feeding. Journal of Neuroendocrinology, , e12584.

Li, S. H., \& Graham, B. M. (2017). Why are women so vulnerable to anxiety, trauma-related and stress-related disorders? the potential role of sex hormones. The Lancet Psychiatry, 4(1), 73-82.

Long, C. G., Blundell, J. E., \& Finlayson, G. (2015). A systematic review of the application and correlates of YFAS-diagnosed 'food addiction' in humans: Are eating-related 'addictions' a cause for concern or empty concepts? Obesity Facts, 8(6), 386-401. doi:10.1159/000442403 [doi]

McCarthy, M., McDonald, C., Brooks, P., \& Goldman, D. (1996). An anxiolytic action of oxytocin is enhanced by estrogen in the mouse. Physiology \& Behavior, 60(5), 1209-1215.

Mccullough, M. E., Churchland, P. S., \& Mendez, A. J. (2013). Problems with measuring peripheral oxytocin: Can the data on oxytocin and human behavior be trusted? Neuroscience and Biobehavioral Reviews, 37(8), 1485-1492. doi:10.1016/j.neubiorev.2013.04.018 
McGregor, I. S., \& Bowen, M. T. (2012). Breaking the loop: Oxytocin as a potential treatment for drug addiction. Hormones and Behavior, 61(3), 331-339.

Meinlschmidt, G., \& Heim, C. (2007). Sensitivity to intranasal oxytocin in adult men with early parental separation. Biological Psychiatry, 61(9), 1109-1111.

Mullis, K., Kay, K., \& Williams, D. L. (2013). Oxytocin action in the ventral tegmental area affects sucrose intake. Brain Research, 1513, 85-91.

Neumann, I. D., Krömer, S. A., Toschi, N., \& Ebner, K. (2000). Brain oxytocin inhibits the (re) activity of the hypothalamo-pituitary-adrenal axis in male rats: Involvement of hypothalamic and limbic brain regions. Regulatory Peptides, 96(1-2), 31-38.

Neumann, I. D., Torner, L., \& Wigger, A. (1999). Brain oxytocin: Differential inhibition of neuroendocrine stress responses and anxiety-related behaviour in virgin, pregnant and lactating rats. Neuroscience, 95(2), 567-575.

Neumann, I. D., Wigger, A., Torner, L., Holsboer, F., \& Landgraf, R. (2000). Brain oxytocin inhibits basal and stress-induced activity of the hypothalamo-pituitary-adrenal axis in male and female rats: Partial action within the paraventricular nucleus. Journal of Neuroendocrinology,

O'connor, D. B., Jones, F., Conner, M., McMillan, B., \& Ferguson, E. (2008). Effects of daily hassles and eating style on eating behavior. Health Psychology, 27(1S), S20.

Oliver, G., Wardle, J., \& Gibson, E. L. (2000). Stress and food choice: A laboratory study. Psychosomatic Medicine, 62(6), 853-865.

Olszewski, P., Waas, J. R., Brooks, L. L., Herisson, F., \& Levine, A. S. (2013). Oxytocin receptor blockade reduces acquisition but not retrieval of taste aversion and blunts responsiveness of amygdala neurons to an aversive stimulus. Peptides, 50, 36-41. 
Onaka, T., Takayanagi, Y., \& Yoshida, M. (2012). Roles of oxytocin neurones in the control of stress, energy metabolism, and social behaviour. Journal of Neuroendocrinology, 24(4), 587-598.

Ott, V., Finlayson, G., Lehnert, H., Heitmann, B., Heinrichs, M., Born, J., \& Hallschmid, M. (2013). Oxytocin reduces reward-driven food intake in humans. Diabetes, 62(10), 3418-3425. doi:10.2337/db13-0663 [doi]

Pecoraro, N., Reyes, F., Gomez, F., Bhargava, A., \& Dallman, M. F. (2004). Chronic stress promotes palatable feeding, which reduces signs of stress: Feedforward and feedback effects of chronic stress. Endocrinology, 145(8), 3754-3762.

Petersson, M. (2002a). Cardiovascular effects of oxytocin. Progress in brain research (pp. 281-288) Elsevier.

Petersson, M. (2002b). Oxytocin decreases plasma levels of thyroid-stimulating hormone and thyroid hormones in rats. Regulatory Peptides, 108(2-3), 83-87. doi:S0167011502001131 [pii]

Pliner, P., \& Mann, N. (2004). Influence of social norms and palatability on amount consumed and food choice. Appetite, 42(2), 227-237.

Riad-Fahmy, D., Read, G. F., Gaskell, S. J., Dyas, J., \& Hindawi, R. (1979). A simple, direct radioimmunoassay for plasma cortisol, featuring a 125I radioligand and a solid-phase separation technique. Clinical Chemistry, 25(5), 665-668.

Rilling, J. K., DeMarco, A. C., Hackett, P. D., Chen, X., Gautam, P., Stair, S., . . Patel, R. (2014). Sex differences in the neural and behavioral response to intranasal oxytocin and vasopressin during human social interaction. Psychoneuroendocrinology, 39, 237-248.

Rubin, Z. (1970). Measurement of romantic love. Journal of Personality and Social Psychology, 16(2), 265. 
Sabatier, N., Leng, G., \& Menzies, J. (2014). Oxytocin, feeding, and satiety. Neuropeptide GPCRs in Neuroendocrinology, , 83.

Schlaug, G. (2017). Harvard neuroimaging lab for music and the brain. Retrieved from http://www.musicianbrain.com/pitchtest/

Sclafani, A., Rinaman, L., Vollmer, R. R., \& Amico, J. A. (2007). Oxytocin knockout mice demonstrate enhanced intake of sweet and nonsweet carbohydrate solutions. American Journal of Physiology.Regulatory, Integrative and Comparative Physiology, 292(5), R1828-33. doi:00826.2006 [pii]

Smith, A. (1967). The serial sevens subtraction test. Archives of Neurology, 17(1), 78-80.

Snyder, M. (1974). Self-monitoring of expressive behavior. Journal of Personality and Social Psychology, 30(4), 526.

Spielberger, C. D., Gorsuch, R. L., \& Lushene, R. E. (1970). Manual for the state-trait anxiety inventory.

Stricker, E. M., \& Verbalis, J. G. (1986). Interaction of osmotic and volume stimuli in regulation of neurohypophyseal secretion in rats. The American Journal of Physiology, 250(2 Pt 2), R267-75.

Thienel, M., Fritsche, A., Heinrichs, M., Peter, A., Ewers, M., Lehnert, H., . . Hallschmid, M. (2016). Oxytocin's inhibitory effect on food intake is stronger in obese than normal-weight men. International Journal of Obesity (2005), 40(11), 1707-1714. doi:10.1038/ijo.2016.149

Tomiyama, A. J., Dallman, M. F., \& Epel, E. S. (2011). Comfort food is comforting to those most stressed: Evidence of the chronic stress response network in high stress women. Psychoneuroendocrinology, 36(10), 1513-1519.

Tops, M., Van Peer, J. M., Korf, J., Wijers, A. A., \& Tucker, D. M. (2007). Anxiety, cortisol, and attachment predict plasma oxytocin. Psychophysiology, 44(3), 444-449. 
Uvnas-Moberg, K. (1997). Oxytocin linked antistress effects--the relaxation and growth response. Acta Physiologica Scandinavica.Supplementum, 640, 38-42.

Van Strien, T., Frijters, J. E., Bergers, G., \& Defares, P. B. (1986). The dutch eating behavior questionnaire (DEBQ) for assessment of restrained, emotional, and external eating behavior. International Journal of Eating Disorders, 5(2), 295-315.

van Strien, T., Gibson, E.L., Baños, R., Cebolla, A., Winkens, L.H.H. (2019). Is comfort food actually comforting for emotional eaters? A (moderated) mediation analysis. Physiology \& Behavior. 211, Sep. 1:112671. doi: 10.1016/j.physbeh.2019.112671. [Epub ahead of print]

Volkow, N. D., Wang, G., Fowler, J. S., Tomasi, D., Telang, F., \& Baler, R. (2010). Addiction: Decreased reward sensitivity and increased expectation sensitivity conspire to overwhelm the brain's control circuit. Bioessays, 32(9), 748-755.

Wardle, J. (1987). Eating style: A validation study of the dutch eating behaviour questionnaire in normal subjects and women with eating disorders. Journal of Psychosomatic Research, 31(2), $161-169$.

Wardle, J., \& Gibson, E. L. (2016). Chapter 55 - diet and stress: Interactions with emotions and behavior. In G. Fink (Ed.), Stress: Concepts, cognition, emotion, and behavior (pp. 435-443). San Diego: Academic Press. doi:https://doi.org/10.1016/B978-0-12-800951-2.00058-3

Young, L. J., Wang, Z., Donaldson, R., \& Rissman, E. F. (1998). Estrogen receptor $\alpha$ is essential for induction of oxytocin receptor by estrogen. Neuroreport, 9(5), 933-936.

Zanos, P., Georgiou, P., Weber, C., Robinson, F., Kouimtsidis, C., Niforooshan, R., \& Bailey, A. (2018). Oxytocin and opioid addiction revisited: Old drug, new applications. British Journal of Pharmacology, 175(14), 2809-2824. 
Zanos, P., Wright, S. R., Georgiou, P., Yoo, J. H., Ledent, C., Hourani, S. M., . . Bailey, A. (2014). Chronic methamphetamine treatment induces oxytocin receptor up-regulation in the amygdala and hypothalamus via an adenosine A 2A receptor-independent mechanism. Pharmacology Biochemistry and Behavior, 119, 72-79. 